\title{
Simultaneous bilateral femoral neck fractures in a dialysis-dependent patient: case report and literature review
}

\author{
Yunyun Zhu', Jingtao $\mathrm{Hu}^{2}$, Wenlun Han'1, Jianwei $\mathrm{Lu}^{3}$ and Yuqing Zeng ${ }^{3^{*}}$
}

\begin{abstract}
Background: Simultaneous bilateral femoral neck fractures are extremely rare without obvious injury. Herein, we report the case of a patient on dialysis presenting with bilateral femoral neck fractures, which is a condition with high complication and mortality rates according to a review of the pertinent literature.

Case presentation: We report the case a 47-year-old female with a history of 8 years of haemodialysis due to polycystic kidney disease who presented with bilateral hip pain during walking. The clinical history and results of physical and radiographic examinations of this patient are shown. Single-stage bilateral hemiarthroplasty was performed after a multidisciplinary team consultation. Three days after the operation, she could ambulate with a walker. The woman gradually regained her previous ability to walk over 6 months after surgery.

Conclusions: A multidisciplinary team consultation for perioperative management is necessary and effective in patients on dialysis. Early diagnosis with prompt surgical treatment could lead to favourable recovery.
\end{abstract}

Keywords: Femoral neck fractures, Bilateral, Dialysis, Osteoporosis, Case report

\section{Background}

Renal osteodystrophy (RO) secondary to chronic kidney disease (CKD) is an established cause of pathological femur neck fractures [1]. The incidence of hip fracture in patients undergoing haemodialysis (HD) is significantly higher than that in the general population. The incidence of hip fracture in dialysis patients is 4.4 times higher than that of the general population [2], and its incidence is 29.3 / 1000 people / year [3]. However, simultaneous bilateral femoral neck fractures (SBFNFs) in patients on dialysis are extremely uncommon [4]. We report a rare case of SBFNFs in a middle-aged patient on dialysis and review SBFNFs in patients with CKD.

* Correspondence: z.yuq@163.com

${ }^{3}$ Department of Orthopaedics, Tongde Hospital of Zhejiang Province, 234 GuCui Road, HangZhou 310012, Zhejiang Province, China

Full list of author information is available at the end of the article

\section{Case presentation}

The patient was a 47-year-old female with no history of trauma who developed bilateral hip pain 1 day prior to admission. She had a history of haemodialysis due to polycystic kidney disease. Upon physical examination, she demonstrated inability to move the hip joints and bilateral inguinal tenderness. Laboratory studies showed anaemia (haemogram $8.5 \mathrm{~g} / \mathrm{dL}$ ), a low normal albumin value $(3.1 \mathrm{~g} / \mathrm{dL})$, a high parathyroid hormone level $(907$ $\mathrm{pg} / \mathrm{ml})$, hypocalcaemia $(5.1 \mathrm{mg} / \mathrm{dL})$, hyperphosphatemia $(2.3 \mathrm{mmol} / \mathrm{L})$, and elevated alkaline phosphatase activity (1228 U/dL). Hip X-ray (Fig. 1a) and CT (Fig. 1b, Fig. 1c) examinations showed bilateral femoral displaced fractures. Bone mineral density testing revealed osteoporosis $(\mathrm{T}=$ 3.0). She also had a history of hyperparathyroidism secondary to CKD and parathyroidectomy.

We promptly performed a multidisciplinary team consultation to make preoperative preparations and performed the surgery 4 days after admission. Considering 


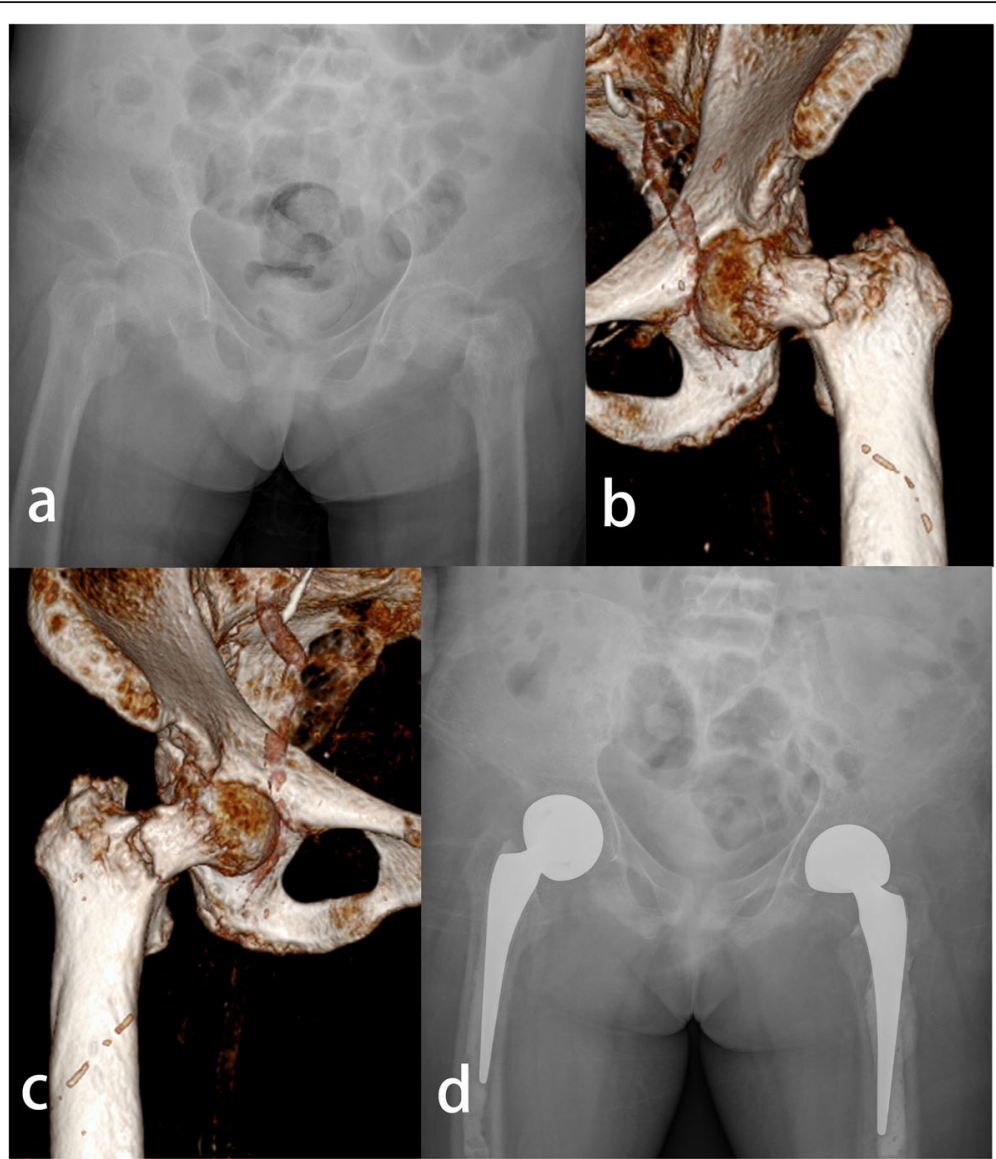

Fig. 1 a: Hip X-ray showing bilateral femoral displaced fractures with low bone density. $\mathbf{b}$ : CT scan showing the femoral displaced fracture on the left side. c: CT scan showing the femoral displaced fracture on the right side. $\mathbf{d}$ : Bilateral femoral displaced fractures treated with bilateral hip hemiarthroplasty

her mobility and life expectancy, we performed concurrent bilateral hip hemiarthroplasty with cement prostheses (Fig. 1d). The operative findings included severe osteoporosis and displaced femoral neck fractures. Anti-osteoporosis medication was administered after surgery. Meanwhile, the patient continued maintenance haemodialysis. Three days after the operation, she could ambulate with a walker. The follow-up appointments at 3 and 6 months revealed that the woman had gradually regained her previous ability to walk.

\section{Discussion and conclusions}

SBFNFs in patients on dialysis are relatively rare. To the best of our knowledge, only 10 cases have been reported previously, making our case the 11th (Table 1) [1,5-14]. SBFNFs are usually secondary to seizure disorders [15], trauma [16], electric shock injuries [17], hypovitaminosis D [18], osteoporosis [19], and metabolic diseases. Stress fractures of the bilateral femoral neck occasionally occur in young patients [20]. It has been reported that the incidence of hip fractures in the general population has decreased significantly [21]. In the contrary, the incidence of hip fractures among haemodialysis patients is increasing [22, 23]. However, in Japan, compared to the general population, in Japanese dialysis patients, the incidence of hip fractures decreased among women but did not change among men between 2008 and 2013 [24]. Although the incidence of hip fractures appears to have decreased slightly, it remains a challenging problem in dialysis patients for both orthopaedic surgeons and nephrologists [25].

Among end-stage renal disease (ESRD) patients, HD is associated with a $61 \%$ higher risk of hip fracture than peritoneal dialysis (PD) [26]. Nevertheless, PD, HD, and kidney transplantation (KT) patients and $\mathrm{HD}$ and $\mathrm{KT}$ patients had the highest and lowest risk of hip fractures, respectively [27]. One study found that an advanced age, low body weight, low serum albumin level, and high alkaline phosphatase (ALP) and parathyroid hormone levels were associated with a low bone mass in HD patients [28]. The patient in our case had a parathyroid hormone level of more than $5000 \mathrm{pg} / \mathrm{ml}$ until undergoing parathyroidectomy. Thus, we suggest thatmaintaining an adequate body weight and serum albumin level, 
Table 1 Summary of all studies in the English literature reporting bilateral pathological neck femur fractures in chronic renal disease

\begin{tabular}{|c|c|c|c|c|c|c|c|c|}
\hline No & Reference & Year & No. of cases & SEX & Age & Primary renal & Treatment & $\begin{array}{l}\text { Dialysis } \\
(\mathrm{Y} / \mathrm{N})\end{array}$ \\
\hline 1 & Zingraf et al. [5] & 1974 & 1 & & 45 & Unknown & Arthroplasty & Y \\
\hline 2 & Gerster et al. [6] & 1983 & $\begin{array}{l}1 \text { out of } 2 \text { cases } \\
\text { reported had CRF }\end{array}$ & $\begin{array}{l}\text { Case 1: F } \\
\text { Case 2: F }\end{array}$ & $\begin{array}{l}\text { Case 1: } 69 \\
\text { Case 2: } 78\end{array}$ & $\begin{array}{l}\text { Case 1: CP } \\
\text { Case 2: Unknown }\end{array}$ & $\begin{array}{l}\text { Case 1: bilateral THR } \\
\text { Case 2: Conservative for } \\
\text { right hip and Osteosynthesis } \\
\text { for left intertrochanteric hip }\end{array}$ & $\begin{array}{l}\text { Case 1: N } \\
\text { Case 2: N }\end{array}$ \\
\hline 3 & Ogun et al. [7] & 2001 & 2 & $\begin{array}{l}\text { Case 1: } \mathrm{M} \\
\text { Case 2: } \mathrm{M}\end{array}$ & $\begin{array}{l}\text { Case 1:45 } \\
\text { Case 2:35 }\end{array}$ & $\begin{array}{l}\text { Case 1: amyloidosis } \\
\text { Case 2: nephrolithiasis }\end{array}$ & $\begin{array}{l}\text { Osteosynthesis with multiple } \\
\text { cannulated screws in both } \\
\text { cases }\end{array}$ & $\begin{array}{l}\text { Case 1: N } \\
\text { Case 2: N }\end{array}$ \\
\hline 4 & Hung et al. [8] & 2001 & 1 & $\mathrm{~F}$ & 39 & Unknown & Bilateral hemiarthroplasty & $N$ \\
\hline 5 & Karapinar et al. [1] & 2003 & 1 & M & 23 & Obstructive uropathy & Bilateral cemented THA & Y \\
\hline 6 & Devkota et al. [9] & 2013 & 1 & $\mathrm{~F}$ & 47 & $\mathrm{DN}$ and $\mathrm{HN}$ & Non-operative management & Y \\
\hline 7 & Garcia et al. [10] & 2014 & 1 & $\mathrm{~F}$ & 43 & Reflux nephropathy & Osteosynthesis & Y \\
\hline 8 & Satyanarayana et al. [11] & 2015 & 1 & M & 23 & Reflux nephropathy & $\begin{array}{l}\text { Bilateral, uncemented, modular } \\
\text { bipolar hemiarthroplasty }\end{array}$ & Y \\
\hline 9 & Mazzola et al. [12] & 2015 & 1 & $\mathrm{~F}$ & 76 & Unknown & $\begin{array}{l}\text { right cemented hemiarthroplasty } \\
\text { and left fixation with dynamic } \\
\text { hip screw }\end{array}$ & Y \\
\hline 10 & Freitas et al. [13] & 2016 & 1 & $\mathrm{~F}$ & 49 & Unknown & Bilateral total hip arthroplasty & Y \\
\hline 11 & John et al. [14] & 2018 & 3 & $\begin{array}{l}\text { case1:M } \\
\text { case2: } \mathrm{F} \\
\text { case3.M }\end{array}$ & $\begin{array}{l}\text { case } 1: 44 \\
\text { case2:15 } \\
\text { case3.64 }\end{array}$ & $\begin{array}{l}\text { PKD } \\
\text { CDK } \\
\text { CP }\end{array}$ & $\begin{array}{l}\text { Osteosynthesis } \\
\text { Osteosynthesis } \\
\text { Conservative (infected) }\end{array}$ & $\begin{array}{l}\text { case1:Y } \\
\text { case2:Y } \\
\text { case3.Y }\end{array}$ \\
\hline 12 & current study & 2020 & 1 & $\mathrm{~F}$ & 47 & PKD & $\begin{array}{l}\text { bilateral hip hemiarthoplasty } \\
\text { with cement prosthesis } \\
\text { concurrently }\end{array}$ & Y \\
\hline
\end{tabular}

Abbreviations: $F$ female, $M$ male, chronic pyelonephritis $C P$ congenital dysplastic kidneys $C D K$, $D N$ diabetic nephropathy, $H N$ hypertensive nephropathy, $P K D$ polycystic kidney disease

regular monitoring of the femoral neck bone mineral density, and undertaking an exercise programme are important to improve bone health in patients on HD.

Guidelines recommend that surgery for hip fracture should be performed within $48 \mathrm{~h}$ after the event. Delayed surgery for more than $48 \mathrm{~h}$ in elderly patients with hip fractures increased the risk of postoperative complications. However, in dialysis patients, a delayed operation did not contribute significantly to the mortality rate compared to that in the non-dialysis cohort [29]. The current study found that delaying surgery for a period of time did not negatively impact the incidence of postoperative complications [30].

Hip fractures are a common problem in the ageing population and are associated with significant mortality and morbidity rates. The mortality rate within 1 year after hip fracture is as high as 36\% despite aggressive management, including surgery and rehabilitation [31]. Unfortunately, the incidence, mortality, and medical costs of fractures in patients with kidney disease are much higher than those of ordinary fractures [32, 33]. Patients with CKD often have a longer hospital stay after a fracture, and the chance of going to a skilled nursing facility after discharge is higher than that of patients without CKD. According to reports, more than $80 \%$ of fracture patients with CKD need skilled nursing facility after discharge form the hospital, which is much higher than other complications of CKD [34].

Femoral neck fractures are often treated with either internal fixation or artificial hip replacement. In the general population, treatment is performed according to age, bone quality, and fracture classification. In our case, we performed hemiarthroplasty according to the poor bone quality and life expectancy of less than 10 years. In the patient dependent on dialysis, the outcomes of arthroplasty are well described in the recent literature. Compared to non-dialysis-dependent patients, dialysis patients undergoing arthroplasty have suboptimal results with significantly higher incidence rates of deep venous thrombosis, surgical site infection, need for blood transfusions, wound complications, intensive care unit care, and attentive postoperative rehabilitation, as well as a 10-20 times greater risk of inpatient mortality [35, 36]. Some authors have suggested that arthroplasty should be approached with caution and preferably be delayed until after KT [37, 38]. In our case, blood transfusions were performed, and a seizure occurred 2 weeks after surgery. There are two possible factors may contribute to the high mortality in dialysis patients with hip fracture. The first is the higher prevalence of comorbidities 
and the second is the higher occurrences of postoperative complications. A personized surgical treatment based on specific clinical situations should be planned and carried out using a necessary risk assessment before surgery [39]. It should be noted that biological and mechanical failure can occur in the patients with $\mathrm{RO}$ and osteoporosis after hip fracture surgery [40]. Thus, a team approach involving expert nephrologists, geriatricians and orthopaedic surgeons is highly significant to reduce early complications and mortality. Dialysis patients with hip fracture require multidisciplinary assessment and intervention for the prevention of subsequent osteoporotic fractures. It can be difficult for dialysis patients to participate in rehabilitation while undergoing dialysis. Therefore, clinicians should highly pay attention to their standard rehabilitation.

In conclusion, hip fractures in HD patients pose serious challenges for surgeons. Clinicians should pay more attention to comprehensive treatment methods, which can reduce the morbidity and mortality rates of hip fractures in HD patients. A multidisciplinary team consultation for perioperative management is necessary and effective. Early diagnosis with prompt surgical treatment could lead to favourable recovery.

\section{Abbreviations}

RO: Renal osteodystrophy; HD: Haemodialysis; CKD: Chronic kidney diseases; SBFNF: Simultaneous bilateral neck femoral fractures; PD: Peritoneal dialysis; $\mathrm{KT}$ : Kidney transplantation

\section{Acknowledgements}

Not applicable.

\section{Authors' contributions}

JWL, WLH, JTH and YQZ participated in the diagnosis and treatment of the patient, provided follow-up, acquired clinical data, drafted and reviewed the manuscript. YYZ and YQZ conducted investigations, reviewed literature, and assisted in polishing the manuscript for final publication. All of the authors read and approved the final manuscript.

\section{Funding}

No funding was received for this study..

\section{Availability of data and materials}

The datasets used and analysed during the current study are available from the corresponding author on reasonable request.

\section{Ethics approval and consent to participate}

Not applicable.

\section{Consent for publication}

The written consent to publish images or other personal or clinical details of participants was obtained from the patient.

\section{Competing interests}

The authors declare that they have no competing interests.

\section{Author details}

${ }^{1}$ Department of Nephrology, Tongde Hospital of Zhejiang Province, HangZhou, Zhejiang Province, China. ${ }^{2}$ Zhejiang Chinese Medical University, HangZhou, Zhejiang Province, China. ${ }^{3}$ Department of Orthopaedics, Tongde Hospital of Zhejiang Province, 234 GuCui Road, HangZhou 310012, Zhejiang Province, China.
Received: 7 March 2020 Accepted: 13 April 2020

Published online: 15 April 2020

\section{References}

1. Karapinar H, Ozdemir M, Akyol S, Ulku O. Spontaneous bilateral femoral neck fractures in a young adult with chronic renal failure. Acta Orthop Belg. 2003:69(1):82-5.

2. Alem AM, Sherrard DJ, Gillen DL, Weiss NS, Beresford SA, Heckbert SR, et al. Increased risk of hip fracture among patients with end-stage renal disease. Kidney Int. 2000;58(1):396-9.

3. Nair SS, Mitani AA, Goldstein BA, Chertow GM, Lowenberg DW Winkelmayer WC. Temporal Trends in the Incidence, Treatment, and Outcomes of Hip Fracture in Older Patients Initiating Dialysis in the United States. Clin J Am Soc Nephrol. 2013;8(8):1336-42.

4. Yassin A, Jawad I, Coomber R, Gonzalez-Castro A. Non-traumatic, bilateral subcapital femoral fractures postpartum. BMJ Case Rep. 2014;2014.

5. Zingraff J, Drueke T, Roux JP, Rondon-Nucete M, Man NK, Jungers $P$. Bilateral fracture of the femoral neck complicating uremic bone disease prior to chronic hemodialysis. Clin Nephrol. 1974;2(2):73-5.

6. Gerster JC, Charhon SA, Jaeger P, Boivin G, Briancon D, Rostan A, et al Bilateral fractures of femoral neck in patients with moderate renal failure receiving fluoride for spinal osteoporosis. Br Med J (Clin Res Ed). 1983; 287(6394):723-5.

7. Ogun TC, Memik R, Yel M, Sarlak A. Bilateral pathologic femoral neck fracture as a consequence of renal osteodystrophy: report of two cases and review of the literature. Artroplasti Artroskopik Cerrahi. 2001;12:199-202.

8. Hung KH, Lee CT, Gau YL, Chen JB. Neglected bilateral femoral neck fractures in a patient with end-stage renal disease before chronic dialysis. Ren Fail. 2001;23(6):827-31.

9. Devkota P, Ahmad S. Bilateral impacted femoral neck fracture in a renal disease patient. Niger Med J. 2013;54(5):354-5.

10. Garcia FL, Dalio RB, Sugo AT, Picado CH. Bilateral spontaneous fracturing of the femoral neck in a patient with renal osteodystrophy. Rev Bras Ortop. 2014;49(5):540-2.

11. Sathyanarayana V, Patel MT, Raghavan S, Naresh D. Simultaneous bilateral femur neck fracture in a young adult with chronic renal failure- a case report and review of literature. J Orthop Case Rep. 2015;5(4):24-6.

12. Mazzola P, Anzuini A, Picone D, De Filippi F, Dubner L, Bellelli G, et al. Simultaneous bilateral femoral neck fracture and end-stage renal disease in a 76-year-old woman: a case report. Aging Clin Exp Res. 2015;27(4):555-9.

13. Freitas A, de Macedo Neto SL, Loures FB, Neto EDS, de Alencar Barreto LC, Camilo MS. Simultaneous bilateral femoral neck fracture in a patient with renal osteodystrophy. Trauma Case Rep. 2016;3:26-31.

14. John R, Kumar P, Aggarwal S, Rajnish RK, Agarwal S, Vatsyan K. Simultaneous, non-traumatic, bilateral neck femur fractures in uremic renal Osteodystrophy: a report of three cases and literature review. J Orthop Case Rep. 2018:8(2):90-4

15. Brennan SA, O'Neill CJ, Tarazi M, Moran R. Bilateral neck of femur fractures secondary to seizure. Pract Neurol. 2013;13(6):420-1.

16. Gao YS, Zhu ZH, Zhang CQ. Simultaneous bilateral fractures of the femoral neck caused by high energy: a case report and literature review. Chin J Traumatol. 2015;18(5):304-6.

17. Sohal HS, Goyal D. Simultaneous bilateral femoral neck fractures after electrical shock injury: a case report. Chin J Traumatol. 2013;16(2):126-8.

18. Paraliticci G, David Rodriguez-Quintana R, Davila A, Otero-Lopez A. Atraumatic bilateral femoral neck fractures in a premenopausal female with hypovitaminosis D. Bol Asoc Med P R. 2015;107(1):51-4.

19. Emami MJ, Abdollahpour HR, Kazemi AR, Vosoughi AR. Bilateral subcapital femoral neck fractures secondary to transient osteoporosis during pregnancy: a case report. J Orthop Surg (Hong Kong). 2012;20(2):260-2.

20. Jasqui-Remba S, Jasqui-Bucay Alan, Jasqui-Bucay Ariel, Fernandez-De-LaraBarrera Y. Bilateral femoral neck stress fractures in a high-performance young female runner. BMJ Case Rep. 2019;12(8).

21. Wright NC, Saag KG, Curtis JR, Smith WK, Kilgore ML, Morrisey MA, et al. Recent trends in hip fracture rates by race/ethnicity among older US adults. J Bone Miner Res. 2012;27(11):2325-32.

22. Wagner J, Jhaveri KD, Rosen L, Sunday S, Mathew AT, Fishbane S. Increased bone fractures among elderly United States hemodialysis patients. Nephrol Dial Transplant. 2014;29(1):146-51. 
23. Arneson TJ, Li S, Liu J, Kilpatrick RD, Newsome BB, St Peter WL. Trends in hip fracture rates in US hemodialysis patients, 1993-2010. Am J Kidney Dis. 2013;62(4):747-54.

24. Wakasugi M, Kazama JJ, Wada A, Hamano T, Masakane I, Narita I. Hip fracture trends in Japanese Dialysis patients, 2008-2013. Am J Kidney Dis. 2018;71(2):173-81.

25. Denburg M, Nickolas TL. Declining hip fracture rates in Dialysis patients: is this winning the war? Am J Kidney Dis. 2018;71(2):154-6.

26. Boonpheng B, Thongprayoon C, Mao MA, Wijarnpreecha K, Bathini T, Kaewput $W$, et al. Risk of hip fracture in patients on hemodialysis versus peritoneal dialysis: a meta-analysis of observational studies. J Evid Based Med. 2019;12(2):98-104.

27. Tan J, Li Y, Wu Z, Zhao J. Risk of hip fracture in patients on dialysis or kidney transplant: a meta-analysis of 14 cohort studies. Ther Clin Risk Manag. 2018;14:1747-55.

28. Huang GS, Chu TS, Lou MF, Hwang SL, Yang RS. Factors associated with low bone mass in the hemodialysis patients--a cross-sectional correlation study. BMC Musculoskelet Disord. 2009;10:60.

29. Swift O, Ayub A, Mathavakkannan S, de Roeck N. Outcomes following surgery for fractured neck of femur in dialysis patients: a 5-year review from a district general hospital in the United Kingdom. BMC Nephrol. 2016;17:26.

30. Dong C, Wang Y, Wang Z, Wang Y, Wu S, Du Q, et al. Damage control orthopedics management as vital procedure in elderly patients with femoral neck fractures complicated with chronic renal failure: a retrospective cohort study. PLoS One. 2016;11(5):e0154906.

31. Bhandari M, Devereaux PJ, Swiontkowski MF, Tornetta P 3rd, Obremskey W, Koval KJ, et al. Internal fixation compared with arthroplasty for displaced fractures of the femoral neck. A meta-analysis. J Bone Joint Surg Am. 2003; 85(9):1673-81.

32. Kim SM, Long J, Montez-Rath M, Leonard M, Chertow GM. Hip fracture in patients with non-Dialysis-requiring chronic kidney disease. J Bone Miner Res. 2016;31(10):1803-9.

33. Beaubrun AC, Kilpatrick RD, Freburger JK, Bradbury BD, Wang L, Brookhart MA. Temporal trends in fracture rates and postdischarge outcomes among hemodialysis patients. J Am Soc Nephrol. 2013;24(9):1461-9.

34. Doan QV, Gleeson M, Kim J, Borker R, Griffiths R, Dubois RW. Economic burden of cardiovascular events and fractures among patients with endstage renal disease. Curr Med Res Opin. 2007;23(7):1561-9.

35. Patterson JT, Tillinghast K, Ward D. Dialysis dependence predicts complications, intensive care unit care, length of stay, and skilled nursing needs in elective primary Total knee and hip Arthroplasty. J Arthroplast. 2018;33(7):2263-7.

36. Erkocak OF, Yoo JY, Restrepo C, Maltenfort MG, Parvizi J. Incidence of infection and Inhospital mortality in patients with chronic renal failure after Total joint Arthroplasty. J Arthroplast. 2016;31(11):2437-41.

37. Cavanaugh PK, Chen AF, Rasouli MR, Post ZD, Orozco FR, Ong AC Complications and mortality in chronic renal failure patients undergoing Total joint Arthroplasty: a comparison between Dialysis and renal transplant patients. J Arthroplast. 2016;31(2):465-72.

38. Ponnusamy KE, Jain A, Thakkar SC, Sterling RS, Skolasky RL, Khanuja HS. Inpatient mortality and morbidity for Dialysis-dependent patients undergoing primary Total hip or knee Arthroplasty. J Bone Joint Surg Am. 2015;97(16):1326-32.

39. Pedersen AB, Christiansen CF, Gammelager H, Kahlert J, Sorensen HT. Risk of acute renal failure and mortality after surgery for a fracture of the hip: a population-based cohort study. Bone Joint J. 2016;98-b(8):1112-8.

40. Song KS, Yoon SP, Lee SK, Lee SH, Yang BS, Park BM, et al. The results of proximal femoral nail for intertrochanteric fracture in hemodialysis patient. Hip Pelvis. 2017;29(1):54-61.

\section{Publisher's Note}

Springer Nature remains neutral with regard to jurisdictional claims in published maps and institutional affiliations.

Ready to submit your research? Choose BMC and benefit from:

- fast, convenient online submission

- thorough peer review by experienced researchers in your field

- rapid publication on acceptance

- support for research data, including large and complex data types

- gold Open Access which fosters wider collaboration and increased citations

- maximum visibility for your research: over $100 \mathrm{M}$ website views per year

At BMC, research is always in progress.

Learn more biomedcentral.com/submissions 